\title{
Can the Archaeology of Manual Specialization Tell Us Anything About Language Evolution? A Survey of the State of Play
}

\author{
James Steele \& Natalie Uomini
}

\begin{abstract}
In this review and position paper we explore the neural substrates for manual specialization and their possible connection with language and speech. We focus on two contrasting hypotheses of the origins of language and manual specialization: the language-first scenario and the tool-use-first scenario. Each one makes specific predictions about hand-use in nonhuman primates, as well as about the necessity of an association between speech adaptations and population-level right-handedness in the archaeological and fossil records. The concept of handedness is reformulated for archaeologists in terms of manual role specialization, using Guiard's model of asymmetric bimanual coordination. This focuses our attention on skilled bimanual tasks in which both upper limbs play complementary roles. We review work eliciting non-human primate hand preferences in co-ordinated bimanual tasks, and relevant archaeological data for estimating the presence or absence of a population-level bias to the right hand as the manipulator in extinct hominin species and in the early prehistory of our own species.
\end{abstract}

\begin{abstract}
Neural substrates of manual specialization, and the possibility of an association with language and speech
\end{abstract}

Right-handedness as a population-level bias is often said to be a defining feature of our species, but a complete evolutionary explanation continues to elude us. One reason for being interested in the evolution of human hand specialization is that it may be a marker of the evolution of speech and/or language. Many psycholinguists and cognitive scientists would dispute such an association, arguing that language processes are sui generis, and that child language development is entirely decoupled from development in other areas (such as manual praxis and manual lateralization). Strong evidence in support of such a position would come in the form of clear and commonly-occurring double dissociations of praxic and linguistic deficits in stroke patients with localized brain damage; clear evidence for specific language impairments without associated manual praxic deficits (and the converse) in individuals with damage to relevant genes (such as the human form of FOXP2); a lack of statistically significant associations between hand preferences and hemispheric dominance for speech processing; and/or clear evidence for both the presence of human-like handedness and the absence of any linguistic capacity (or the converse) in our closest living relatives, the chimpanzees. In all these cases, however, the evidence is either equivocal or supportive of some degree of association between the language and action systems. We will not review this complex literature here (see, for instance, Bates \& Dick 2002; Corballis 2003b with commentaries; Arbib 2006; Molnar-Szakacs et al. 2006; Willems \& Hagoort 2007; Stout et al. 2008). We will, however, outline three scenarios of the languagehandedness relationship which assume that an association exists, but which lead to contrasting predictions about non-human primate brains and behaviour.

\section{The Homo loquens scenario}

The association most often cited to contextualize handedness research in relation to language evolution is that it is the human left cerebral hemisphere 
which is dominant for organizing complex sequential movements in both language and manual praxis. Typically the assumption might then be that since both language and population-level right-handedness are uniquely human traits, they must both reflect some novel pattern of brain organization that is derived in the human lineage. Since language processes are more strongly left-lateralized (that is, there are more people left-lateralized for speech processing than there are right-handers), it is often further assumed that a population bias towards right-handedness is a secondary consequence of hemispheric specialization for language processes. In that case, the emergence of a bias towards right-handedness in the archaeological record becomes a diagnostic marker of brain adaptations for language and speech (e.g. Crow 1998).

\section{Evidence relevant to the Homo loquens scenario}

Earlier versions of this hypothesis would have predicted that non-human apes and other primates lack left-hemisphere control of tool-use and vocalization. The Homo loquens scenario remains a meaningful avenue of enquiry, but none of the assumptions which its strong (discontinuity) form entails should be exempt from further testing. We will summarize below some relevant findings about behavioural manual laterality in chimpanzees. Comparative evidence for continuities and discontinuities of behavioural and neuroanatomical asymmetry or laterality of function in humans and in other living primates continues to accumulate (for recent reviews see Chance \& Crow 2007; Goble \& Brown 2008; Sherwood et al. 2008). Most relevant to the argument for continuity with other living species are the reports of a left-hemisphere enlargement of the planum temporale (in the region of Wernicke's area) in humans and great apes, and possibly also in Old Word monkeys (Gannon et al. 1998; 2008; Hopkins et al. 1998); a left-hemisphere dominance for the depth and length of inferior frontal sulci in the region of Broca's area in humans and African apes (Cantalupo \& Hopkins 2001); a human-like width petalia pattern in the cerebral hemispheres of great apes but not in monkeys (Hopkins \& Marino 2000; Pilcher et al. 2001); grey matter asymmetries in chimpanzee cerebral hemispheres (Hopkins et al. 2008); evidence of bilateral orofacial and manual gestural control systems in the homologue of Broca's area in macaque monkeys (Rizzolatti \& Arbib 1998; Gentilucci \& Corballis 2006), and evidence of left-hemisphere dominance for responses to same-species vocalizations also in macaques (Poremba et al. 2004; Petkov et al. 2008); left-hemisphere activation in Broca's area associated with manual and vocal communicative gesturing in chimpanzees (Taglialatela et al. 2008); and the finding that chimpanzees in the Yerkes captive population who preferred to use their right hands in communicative gesturing tended to have a larger inferior frontal gyrus in the left hemisphere (Broca's area), compared with chimpanzees that did not display this pattern of hand preference (Taglialatela et al. 2006).

Most relevant to the argument for discontinuity with other living species are the difference in human and non-human primate brain size and the associated rescalings of structure volumes and of grey/white matter ratios (Rilling 2006; see also Gibson \& Jessee 1999) which have been associated with the expectation of greater functional lateralization due to increases in inter-hemispheric conduction delay (Ringo 1991; Ringo et al. 1994; Rilling \& Insel 1999); asymmetries in the proportion of neuropil (the space between neuronal cell bodies occupied by connecting axons, dendrites, and synapses) with a higher proportion of neuropil in the human left hemisphere in Broca's and Wernicke's areas and in the hand area of primary motor cortex, this pattern being absent in the latter two areas in chimpanzees (Amunts et al. 1996; 1997; 1999; 2003; Buxhoeveden et al. 2001; Sherwood et al. 2007); and genetic changes in humans associated with speech or language abilities (e.g. Fisher 2005).

This evidence would seem to refute the arguments for a strong discontinuity between humans and other primates in basic neural organization for language and speech, but rather to support an argument for gradual amplification of pre-existing biases, consolidated by further genetic adaptations, under selection for functional lateralization in the hominin lineages. This does not in itself, however, preclude the language-first scenario for the domain in which those selection pressures were first and/or most strongly expressed.

\section{The Homo faber scenario}

An alternative scenario is also sometimes proposed as a means of bootstrapping the evolution of language out of pre-existing adaptations for manual praxis. Bradshaw \& Nettleton (1982), for example, suggested that the difference between the two hemispheres may relate to a contrast between analytic and holistic processing, with the left hemisphere specialized for movement sequencing and for finer perceptual discrimination of rapidly-changing acoustic signals. They suggested that human lateralization originates in tooluse, which involved 'prolonged, sequential syntactic and recursive routines and subroutines ... almost from the earliest days of the flaked stone industry' (Bradshaw \& Nettleton 1982, 180), and that there would 
have been an advantage to a consistent pattern of hand specialization in groups where implements were being shared and where their use was learned by imitation. In their scenario, population-level right-handedness emerged under selection for social learning and cooperation in tool-use, building on a pre-existing left-hemisphere specialization. They do not have a specific scenario for the subsequent adaptive evolution of speech, although they do comment that 'face and articulatory gestures could have initially perhaps synergistically accompanied manual gestures, and then replaced them' (Bradshaw \& Nettleton 1982, 182).

More recently Arbib (e.g. Roy \& Arbib 2005; Arbib 2006), in particular, has proposed a seven stage 'mirror system' model of the evolution of language which also sees tool-use as a kind of precursor. The first three stages involve the evolution of a simple mirror-neuron based imitation system for manual grasping. The intermediate stages invoked during hominin evolution require that system to evolve through complex imitation of manual praxis (involving the capacity for social learning of longer sequences of novel and hierarchically-organized actions), via a manual protosign stage (involving pantomime gestures by the signaller, with conventionalized gestures to disambiguate the meaning of these pantomimes), to a protolanguage stage in which vocal gestures accompany and 'invade' the communicative domain of these manual gestures. In Arbib's model the first three stages had already been attained in the last common ancestor of humans and chimpanzees, and the last stage (fully grammatical linguistic structure) was perhaps achieved by cumulative cultural evolution in modern humans (and not by genetic adaptation: e.g. Kirby 2000; Kirby et al. 2007). His model does not include any specific predictions about continuity in lateralization of the non-human and human motor systems in the manual system. In an extension of this model by Corballis $(2003 a, b)$ it is proposed that since the mirror system in the monkey and human brain is bilaterally represented, left-lateralization and human handedness would have been associated with the shift to the vocal channel in the sixth 'protolanguage' phase. Left-lateralization of vocal circuitry is held to be phylogenetically old and widespread in extant primates, so that as Corballis (2003a, 197) puts it, 'language may have gone from hand to mouth, while lateralization went from mouth to hand'.

If Bradshaw \& Nettleton (1982) were right, then population-level right-handedness in the stone tool record would indicate cerebral specialization for technology but not necessarily the presence of speech. Since human hemispheric specialization (or processing style) was seen by them as the quantitative elaboration of a qualitative difference already existing in a distant common ancestor shared with apes and perhaps also seen in some monkeys, we might also expect to see some evidence of a population-level right-hand preference for dextrous manipulations in tool-use tasks in non-human primates.

By contrast in Corballis's (2003a,b) adaptation of the Arbib model, the emergence of a bias towards right-handedness in the archaeological record is a diagnostic marker of a vocal protolanguage. The latter hypothesis would predict that non-human apes and other primates share with humans the left-hemisphere control of vocalization. In Corballis's view, the reason for nonetheless invoking an intermediate phase of manual gesturing to get us from non-human primate vocalization to human spoken language is that nonhuman primate vocalizations are largely emotionally expressive, while their manual actions are more intentionally regulated.

\section{Evidence relevant to the Homo faber scenario}

A conjecture about the antecedents in manual praxis of the frame/content organization of language had been advanced by MacNeilage et al. in 1984, but was subsequently rejected by MacNeilage because he 'was unable to conceive of an adaptation, induced by a specific selection pressure, that would have achieved the transfer of such a generalized organization capability from the manual to the vocal system' (MacNeilage 1998, 510). Similar qualitative arguments were made by Steklis \& Harnad $(1976,450)$, when they observed that

we do not see this analogy [between tool-fashioningand-use and language], except for the fact that both seem to be planned, skilled motor-sequential activity. The latter fact is certainly important ... but it is surely not sufficient to account for the specific origins of language, nor to account for those critical cognitive characteristics in which language differs from all other forms of planned sequential behaviour.

Bradshaw (1991), in a follow-up to the 1982 paper written with Nettleton, summarized ten years' worth of new findings indicating that lateralization of perceptual and motor systems was widespread in vertebrates and that a right-hemisphere specialization for emotional and spatial behaviours and a lefthemisphere specialization for some learned, sequential behaviours may even derive from a distant common ancestor of all extant birds and mammals. He also now took the view that 'tool use could not have primarily driven the evolution of brain, intelligence and language, as despite massive increases in brain size, tool kits barely changed until about 300,000 years 
ago' (1991, 49). This does not preclude the possibility that pre-existing functional lateralization came under selection earliest in the domain of manual praxis (as Bradshaw \& Nettleton (1982) had previously argued). However, it would imply that even if population-level right-handedness did first appear in that context, it was not closely coupled to the subsequent evolution of increased brain size and of language circuits. If there is clear evidence for a precursor to population-level righthandedness in the manual praxis of extant non-human primates, and if population-level right-handedness also characterizes the Early Palaeolithic record from a period prior to significant brain expansion (i.e. before Homo ergaster and Homo erectus), then this argument would be supported.

In Corballis's (2003a,b) version of the Arbib model, in contrast, the emergence of a bias towards right-handedness in the archaeological record is a diagnostic marker of a vocal protolanguage. More recent work on the neurology of action understanding has revived interest in the overlapping organization of manual and vocal gestural control (Rizzolatti \& Arbib 1998; Gentilucci \& Corballis 2006; Fogassi \& Ferrari 2007). However, Arbib's tool-use-first scenario does not include any specific predictions about continuity in lateralization of the non-human and human motor systems in the manual system. Indeed Arbib (2006, 1147-8) comments that:

it is worth recalling that the left hemisphere in most humans is dominant for language, so that Broca's area (or, at least, area 44) refers to the F5 homologue in only one hemisphere. However, the F5 mirror system in monkeys is bilateral and thus has homologues in the right as well as the left hemisphere of humans and, indeed, the 'mirror' responses in human neuroimaging tend to be bilateral and distributed in both frontal and parietal cortex.

This bilateral representation of the mirror system would seem not to support the Homo faber scenario, and in defending that hypothesis Arbib is forced to downplay the significance of the human leftlateralized pattern when he says that

\footnotetext{
it is not the case that an innate syntax machine is wired into the left hemisphere and not the right, but rather (to speculate somewhat) that although both hemispheres can learn syntax, the left hemisphere in most people has capabilities that allow it to 'win the race' to acquire early elements of syntax, and that the presence of these assemblies in one hemisphere biases the system to acquire similar structures in nearby areas of cortex $(2006,1149)$.
}

In fact, it has been suggested that the left-lateralization of language processes must derive not from the mirror system per se, but from some pre-existing left-lateralized auditory component (Aziz-Zadeh et al. 2006). As we have seen, some such accommodation is made by Corballis in his version of this model, when he proposes that left-lateralization and handedness would have been associated with the shift to the vocal channel in Arbib's 'protolanguage' phase.

\section{Differences between the two scenarios that might be archaeologically resolvable}

As we have now seen, the strong discontinuity version of the Homo loquens hypothesis seems to be refuted by anatomical and behavioural evidence of primate precursors to the human pattern of lateralization, even if much of the relevant behavioural evidence must be taken as provisional pending further work (Hopkins \& Fernandez-Carriba 2002). However, it remains plausible that the human pattern of population-level right-handedness derives from selection for increased left-hemisphere lateralization of vocal-auditory communicative behaviours, with a secondary consequence of increased frequency of right-handedness due either to an underlying commonality in left-hemisphere processing style in the vocal and manual praxic domains, or to a close pre-existing association between hand and orofacial gestural control at a more specific cortical level. This is the hypothesis both of the Homo loquens scenario, and of Corballis's version of the Homo faber scenario. In both cases, archaeological evidence of population level right-handedness would then be a diagnostic marker of speech adaptations. This would be of fundamental importance for archaeologists in terms of their ability to contribute to languageevolution research, since individual handedness is something that we can often diagnose from fossil and artefact evidence (see below).

In opposition to this we have scenarios which assert the phylogenetic primacy of lateralization of manual praxis, with human population-level right handedness simply a quantitative elaboration of a bias also to be found in great ape behaviour, and with an archaeological record of increasingly prevalent righthandedness expected to emerge with the use of flaked stone tools (and not to be coupled to subsequent brain size increases). If we find both a precursor to population-level right handedness in great apes for manual tool-use tasks, and clear evidence of an increased degree of population-level right handedness in early tool-using hominins of australopithecine grade (which would include those species extant at the time of the early Oldowan), then we might as well give up trying to diagnose language and speech capacities from handedness. The latter may perfectly well have 
significantly preceded the former, by a time interval that we can only estimate using other independent language-diagnostic indicators.

Having established that the stakes are high, we now turn to the behavioural evidence for handedness in extant non-human primates, and to the archaeological evidence for the emergence of a human pattern of population-level right-handedness in earlier hominins.

\section{Handedness in the context of manual specialization}

At this point some clarifications of terms are in order. In the context of human evolution, we usually use the term 'handedness' to denote the allocation of consistent roles to the right and the left hands in a large majority of individuals of a species (the pattern being either reversed, or inconsistent, in the remainder). Handedness thus refers to a population-level bias in hand-use patterns. This corresponds to Level 4 or Level 5 handedness in the scheme of McGrew \& Marchant (1997), who classify the degree of lateralization present in any population sample of primate behaviour in some task or set of tasks with Level 1 indicating an absence of manual specialization in individuals as well as in the whole population, Level 2 indicating some manual specialization in individuals but no consistent bias to one side or the other in the whole population, Level 3 indicating a greater degree of manual specialization to the point of exclusivity in many individuals, but again with no population-level bias, Level 4 indicating some bias towards a particular side in a significant majority of individuals in the population, and Level 5 indicating a stronger bias of that kind (with the majority who favour a particular side using that side exclusively).

Traditional definitions of handedness consider it as resulting from actions performed unimanually and tend to describe the right hand as 'dominant'. This is probably related to the most common methods of measuring handedness in humans, by questionnaires or by noting the writing hand (Bryden 1977; Oldfield 1971). There appear to be degrees of hand preference according to the type of task being tested (Annett 1972; Bishop 1989; Fagard \& Corroyer 2003). In the standard measures of hand preference, lateralization increases with task skillfulness (Healey et al. 1986; Steenhuis \& Bryden 1989). Provins (1997a) invoked the learning of skilled motor actions as a possible mechanism for reinforcing hand preference in tool-use (learning is defined as a permanent neuronal reorganization of motor cortex which facilitates the execution of the motor task: Magill 1993). Because gestures are only learned by practising with the same organ (the transfer of motor skills from one learned hand to the other, unpractised hand is very weak), people tend to rehearse skills with a consistent (bi)manual configuration. A consistent hand-use pattern directly improves the efficiency and performance of the task (Todor \& Doane 1977). Analysis of ethnographic films of the daily lives of people in three traditional cultures (the G/wi Bushmen from the Central Kalahari in Botswana, the Himba from northern Namibia, and the Yanomamö from the Orinoco forest in south Venezuela) revealed both consistent individual preferences and a population bias to right-handedness for using tools, especially where a precision grip was involved, but no consistent hand preference at the individual or the population level for other manual actions (Marchant et al. 1995). Handedness as a consistent division of hand labour occurs primarily in skilled manipulations (Hinckley et al. 1997; Provins 1997b).

However, this exclusive focus on preference patterns for the 'dominant hand' diverts attention from the bimanual co-ordination required in most toolusing tasks. In order to characterize handedness in a way that is relevant to prehistoric tool manufacture and use, a bimanual model is needed. For example, knapping stone involves complex coordinated movements in both hands, with some degree of precision, spatial positioning, and timing necessary for both the right and left upper limbs. In a knapping event, the moment of contact between the hammer and the stone core results from a bimanually differentiated coordination of the core hand/arm with the hammer hand/arm (Stout 2003; Bril et al. 2005; Pelegrin 2005). This kind of coordinated bimanual action, with well-specified roles for each upper limb, can be said to characterize prehistoric object manipulation. In fact, it is likely that very few of the daily activities of prehistoric people were accomplished with only one hand or arm, and certainly most of the supposed activities taking place would have required two-handed coordination, such as working wood and hide, bow shooting, digging, crafting bone and shell ornaments, painting, weaving, spinning, or threshing and grinding grain (Eshed et al. 2004). Therefore a useful model will be one that accounts for the actions of both hands, rather than focussing only on a single 'dominant' hand.

The definition used here is adapted from Guiard's (1987a) model of asymmetric bimanual coordination as it applies to skilled tool manufacture and use. ${ }^{1}$ In this model, one hand and/or arm performs movements which Guiard qualifies as high-frequency, being more temporally and spatially precise (i.e. being faster and having a narrower target), whereas the other upper 
limb is low-frequency, acting as a stabilizer or support, maintaining the spatial or temporal structure, and moving earlier to define the spatial reference frame. To define the group-level handedness that is specific to humans, Guiard suggested that most humans tend to learn the low-frequency role with the left hand and the high-frequency component with the right hand. The model is endorsed by Hinckley's experiments (Hinckley 1996; Hinckley et al. 1997), in which subjects maintained the stabilizing role of the left hand and the manipulative role of the right hand even when the test objects were switched to opposite hands. Another example is in handwriting, where the left hand stabilizes the paper, actively moving it around, while the right hand manipulates the pen (Athènes et al. 2004). One common Palaeolithic task, scraping hides, which is often described as unimanual according to the hand holding the tool, also requires this coordination of both hands: one hand to hold and orient the hide, the other hand to manipulate the scraping tool.

The bimanual coordination model which we have outlined here does not contradict previous scenarios of parallels between handedness and language, which emphasize the executive role of the manipulating hand and the control of complex sequential movements in object manipulation and language processing. Rather, we have supplemented these accounts by drawing attention to the complementary role of the supporting hand, and suggested that a full account of manual praxis and of the neural organization of language needs to take this into account. Learning, planning and executing complex sequential movements with either hand (right or left) seems to require activation of the left hemisphere in right-handers: this observation goes back to Liepmann's (1905) studies of the effects of left- and right-hemisphere damage on apraxic syndromes and continues to find support (Grafton et al. 2002; Haaland et al. 2004; Verstynen et al. 2005). The right hemisphere, in addition to its role in controlling the left hand (on which the activation pattern just mentioned is superimposed), seems to be important for visuoperceptual aspects of tool manipulation tasks (Sakata \& Taira 1994).

\section{Manual specialization in other living primates}

Manual specialization in living non-human primates has been extensively studied, with particular importance attached to resolving the question of continuity or discontinuity between the human and non-human patterns (because of the implications for the evolution of human cognitive adaptations). MacNeilage et al. (1987) suggested that primates are characterized by a phylogenetically older left-hand specialization for visually-guided reaching, which is supplemented in anthropoid primates by a right-hand (left-hemisphere) specialization for manipulation. Commentators on this article criticized its assessment of the evidence in support of this hypothesis, among those commentators Guiard himself, who proposed instead that human bimanual coordination was characterized by a unique combination of right-hand specialization for finer-grained movements; left-hand precedence in the temporal order of initiation of a bimanual task; and left hand defining the spatial reference frame (Guiard 1987b, 277).

In subsequent work it has also become apparent that non-human primates must be observed using their hands in complex asymmetric bimanually coordinated tasks if this question of continuity or discontinuity is to be satisfactorily resolved, because such tasks are the most reliable way to elicit hand preferences (e.g. Hopkins \& Rabinowitz 1997). The task which is most frequently used at present to elicit such behaviours is the Tube task (Hopkins et al. 2001), an extractive feeding task involving an opaque PVC tube containing smears of peanut butter which can be extracted if one hand holds the tube while part of the other hand is inserted into it (the apparatus does not permit extraction using the tongue, and attempts to solve the task using the feet to grasp the tube may also occur, but are not typically retained in the analysis). The results of these experiments are usually reported in terms of traditional handedness, i.e. which hand is used as the manipulator that extracts the food, but the task is clearly also an illustration of the specialization of hand roles in Guiard's sense.

In Old and New World monkeys, Bennett et al. (2008) found no population-level bias in hand preference in rhesus macaques in the Tube task. Schmitt et al. (2008) found no population-level bias in hand preference in barbary macaques in the same task. Spinozzi et al. (1998) however did find a population-level right hand preference in capuchin monkeys in a Tube task, and Vauclair et al. (2005) obtained a similar result in a Tube task with baboons.

In captive orangutans, Hopkins et al. (2003) found population-level left-handedness in the Tube task. Among the African apes, Byrne et al. (2001) found a rich repertoire of manual configurations used by mountain gorillas in feeding, frequently deployed in asymmetric bimanually coordinated actions, and eliciting strong lateral preferences in individuals but no significant population-level bias (Byrne \& Byrne 1991). Hopkins et al. (2003) also found no significant population-level hand preference in captive gorillas in the Tube task. 
Similarly, Chapelain \& Hogervorst (2009) found only individual preferences for the Tube task in bonobos.

Hopkins et al. (2004) have, however, found a population-level right-hand preference in the Tube task in three separate captive chimpanzee populations, all with large sample sizes, although the ratio of right- to left-handed individuals is lower than in humans - typically 2:1 in chimpanzees, as compared with 8 or 9:1 in humans - and, furthermore, there are very much higher frequencies of ambipreferent chimpanzees than of ambipreferent humans (Hopkins 2006). A similar pattern has not been reported in wild chimpanzees in asymmetric bimanual coordinated tasks although most wild chimpanzee tool-use is unimanual (e.g. termite fishing, which seems to elicit a left-hand preference in the wild: Lonsdorf \& Hopkins 2005). Some instances of bimanual tooluse such as ant-dipping (McGrew 1974) do exist in which lateral preferences might naturally be elicited, although in the case of ant-dipping the need to use the other hand for postural support seems to contribute to an absence of even Level 3 laterality (consistent within-individual hand preferences) (Marchant \& McGrew 2007). It therefore remains unclear whether the Level 4 population-level right handedness seen in the captive chimpanzee populations studied by Hopkins's group reflects elicitation by a task which has no frequently-observed analogue in the wild, or whether these captive populations contain subjects whose hand preferences have been influenced by the handedness of the humans with whom they interact in the captive setting. Additionally, it is not always clear how far the negative results obtained in the Tube task with other great ape species reflect true species differences in hand-preference distributions, as opposed to uncertainties due to small sample sizes (given the relatively small handedness effect seen in Hopkins's captive chimpanzee samples).

\section{Archaeological evidence for hand roles}

Characterizing the hand roles as low-frequency ('support') and high-frequency ('manipulate') following Guiard's (1987a) terminology leads to specific predictions about hand-use patterns which can be tested with the archaeological findings of lateralized tool manufacture and use. Let us now turn to the Palaeolithic evidence and question whether (and when) we can detect the characteristic human pattern of population-level right handedness for the manipulator role. If the archaeological data match the present-day pattern of bimanual complementarity, then the right hand should perform the manipulative actions requir- ing more precision, accuracy, or speed. Conversely, the left hand should be preferred for stabilizing actions of supporting or positioning objects. Special attention is paid here to tasks that require complementary actions of both hands, whether simultaneous or in sequence. These and other, unimanual tasks are described at greater length in Steele \& Uomini (2005); related osteological evidence is reviewed by Steele $(2000 a, b)$.

Since hand-held percussion methods of stonetool manufacture are necessarily bimanual and complementary, the knapping hand can be considered the manipulative hand. For the specific action of knapping stone, most modern-day knappers hold the hammer in the right hand and the stone being knapped in the left hand (Desrosiers 1997; Uomini 2005). This pattern illustrates the model: the left hand supports the core, maintaining its position relative to the striking arm. The right hand performs a ballistic movement requiring precision both in time and space, in order to strike the core in the correct place and at the correct moment. Ethnographic data also support the model; Stout $(2002,697)$ reports that all of the Papua New Guinea knappers he studied hold the core in the left hand and strike with the right hand. The material culture evidence from knapping techniques, methods and scatters should therefore be consistent with a right-handed model.

\section{Hominins prior to $0.5 \mathrm{Myr}$ вР}

One methodology for determining laterality from flakes was proposed by Toth (1985), based on the location of previous flake scars seen on the dorsal surface of cortical flakes. This methodology rests on the assumption that flakes are removed serially and unidirectionally along the perimeter of a singleplatform core, and that the direction of removal is dictated by the hand holding the core. In Toth's own knapping he reports that he, a right-hander, rotated the core in the predicted direction, and the experiment done by Ludwig \& Harris (1994) also supports his claim. However, three other experiments have not replicated his findings (Patterson \& Sollberger 1986; Pobiner 1999; Uomini 2005). Together these findings would suggest that this particular determinant of handedness is not yet validated for the single-platform core rotation paradigm and should not therefore be applied to other lithic industries. This leaves us with no evidence either for or against manual specialization in hominins prior to 0.5 Mya.

Homo heidelbergensis and Neanderthals

Several experimental knappers have demonstrated clear traces of handedness in knapping scatters. 
Specifically, the concentration of debris tends to be skewed to the side of the knapping hand when sitting on a seat (Fischer 1990; Johansen 1996). If the knapper sits directly on the ground, the scatter is skewed to the side of the core hand and ends abruptly at the hammer-side leg (Newcomer \& Sieveking 1980; WenbanSmith 1997). Knapping scatters are rarely preserved; one European in situ scatter attributable to Homo heidelbergensis has been studied for handedness: at Boxgrove, UK (c. 500,000 вр) there is a left-skewed scatter bounded by the knapper's right leg (Roberts \& Parfitt 1999), consistent with a right-handed knapper.

The diagonal striations frequently found on Homo heidelbergensis and Neanderthal teeth are often interpreted as the result of a specific, lateralized eating activity (Martin 1923; Semenov 1964; Trinkaus 1983). This involves holding a piece of meat with one hand, gripping it between the teeth, and cutting off pieces with a knife held in the other hand. Figure 25 in Weyer $(1959,42)$ illustrates the bimanual configuration that is described by Bailey $(1942,210-11)$ :

Sometimes the meat is grasped with the teeth and the left hand and cut off close to the mouth with a knife, cutting toward the face. Sometimes the piece desired is held in the fingers and severed from the main portion with the knife moving away from the body.

Ethnographic reports from the nineteenth century onward reveal that this practice was not only widespread among Arctic peoples, but was also common for the Kalahari, Amhara, Somali, Blackfoot, Navajo, and Bakairí (references found in the e-HRAF collection, 2003). Importantly, the universal pattern is to hold the meat with the left hand and the knife in the right hand, wherever hand roles are mentioned (Uomini 2008b). Bermúdez de Castro et al. (1988) experimentally replicated the gesture, creating diagonal striations that were oriented downward to the left (from the observer's viewpoint) for a right-hander. This orientation is the predominant one in the striations on fossil teeth, with 15 individuals assigned to Homo heidelbergensis at the Sima de los Huesos Middle Pleistocene site having that pattern predominantly and none having the reverse pattern predominantly (Trinkaus 1983; Lozano et al. 2008, who report the geological age of this sample as older than $0.5 \mathrm{Myr} \mathrm{вр;}$ cf. Bermúdez de Castro et al. 1988; Fernández-Jalvo \& Bermúdez de Castro 1988; Fox \& Frayer 1997; Roberts $\&$ Parfitt 1999). The biomechanics are discussed in detail by Uomini (in press). Because the meat-cutting gesture involves a stabilizing role for the left hand and a manipulative role for the right hand, the fossil data allow us to infer that the roles predicted by the model were maintained by these hominins.
Cornford (1986) assesses handedness in the laterality of resharpening flakes from La Cotte de St Brelade, Jersey, Channel Islands. Her method is based on reconstructing the bimanual configurations that were preferred for knapping long sharpening flakes, to rejuvenate the worn edges of scraper tools. These coup $d u$ tranchet flakes were consistently struck using the same holding position, which was also the one preferred by her right-handed experimental knapper. The assemblages span the time range from 240,000 to 122,000 вр. Out of 1302 unbroken long sharpening flakes, 79 per cent were struck in this way, which Cornford (1986) takes as representing a right-handed preference among the Neanderthal knappers at the site.

Semenov (1964) noted that the diagonal striations often found on bone retouchers indicate the bimanual configuration used during pressure flaking. Specifically, the right hand holds the pressure flaker and the left hand holds the flint piece being retouched; pressure is applied upwards from the right hand to remove spalls from the upper (visible) surface of the flint tool. The optimum configuration is related to the most effective position of the forearms for applying force, making the long axes of the flint and the retoucher meet at an acute angle. This angle produces oblique striations indicating the hand used. The right-handed configuration is evident in the Middle Palaeolithic (Kiik-Koba and Teshik-Tash) retouchers studied by Semenov (1964). Right-oriented marks are also evident on at least one retoucher from Vindija Cave, Croatia (Ahern et al. 2004, 59). Similarly, predominantly rightward striations (10 right and 4 left) may be present on several of the Mousterian bone and stone retouchers from Riparo Tagliente, Italy which are illustrated in Leonardi (1979). In a related vein, striations on butchered bone are a promising future avenue of research since they can show the direction of the cutting motion and thus the butcher's cutting hand (Pickering \& Hensley-Marschand 2008).

\section{Early anatomically modern Homo sapiens}

The right-handed configuration for bone retouchers is also evident in the Upper Palaeolithic (Kostenki 1) retouchers studied by Semenov (1964). Lateralized use-wear is also found on other tool types. Semenov's (1964) reconstructions of the biomechanical determinants of asymmetrical use-wear showed that about 80 per cent of Upper Palaeolithic hand-held end-scrapers from the former USSR (Kostenki 1, Timonovka, Mezin, Suponevo, Sakajia Cave) and other sites (Wadi Diffel and Wadi Mengoub in the Capsian Sahara, Przedmost in Moravia, Magyarbogy in Transylvania, 
Gorge d'Enfer, Font-Robert, El-Mekta, Lespugue, Ercheu, Seriniá, and Campigny) were used in the right hand. This implies that the hide being scraped was held with the left hand, which is consistent with the model.

Another category of evidence for complementary hand role differentiation is found in rock art. Handprints and hand stencils are widely-occurring and span the entire time range of known rock art (Kirchner 1959; Delluc \& Delluc 1993). For stencils it is probable that the stabilizing hand was the one preferred to press against the wall, as confirmed by modern-day experiments in prehistoric painting (Faurie \& Raymond 2005), while the manipulative hand would most likely have been selected to hold the blowing tube and to apply paint to the wall since these require precision. If the hand was dipped in pigment for positive handprints, this would be expected to have been done with the manipulative hand as well. The differential hand preferences for these two kinds of hand representations can be explained by considering the roles of the hands depending on the task. Namely, to make a positive handprint the paintcovered hand is pressed against the wall. Taken alone, this might be qualified as a supporting action due to its slow and spatial nature. However, this action will become the more manipulative role if the other hand is engaged in something much less manipulative, such as holding a pigment container or a torch. In this case it is expected that the supporting role of holding the pigment or torch is taken up by the left hand, leaving the right hand available for the handprint. In contrast, when spraying a negative stencil with a pair of blowing tubes (Clot et al. 1995; Ringot 2003), it is necessary to hold the tubes and pigment container with one hand. This requires very fine control to regulate the positioning of the tubes (N. Uomini pers. obs.) and would thus be preferred by the right hand. Following these assumptions, the hand depicted in stencils is taken to be the supportive hand while the hand in prints is taken as the manipulative hand. In France and Spain, 17 caves yield (in total) more stencils of left hands (228 of 280) (Delluc \& Delluc 1993, 34-5), and this is representative of the distribution in Holocene hunter-gatherer rock-art sites elsewhere in the world (Steele \& Uomini 2005).

In summary, the archaeological data for actions requiring complementary bimanual coordination show a consistent pattern that is identical to the one preferred by a significant majority of living people: the left hand acts in a supporting role while the right hand performs fine manipulations. These data span the time range from the European Lower Palaeolithic to the present, including hominin species from Homo heidelbergensis and Neanderthals to anatomically modern Homo sapiens. There are too few well-validated sources of inference about left and right hand roles in earlier fossil hominins to enable conclusions to be drawn for those cases. All of these observations and interpretations would benefit from further bouts of recording and validation. In addition, characterizing these traits (or their absence) in hominins from the time of and immediately prior to the last common ancestor of those three species would be invaluable. Future work could usefully be directed at characterizing the population distribution of hand preferences in tool use in Homo ergaster/erectus from early Acheulean biface characteristics (for those made by H. heidelbergensis in Europe see Ashton 1988; White 1998; Uomini 2008a).

\section{Conclusions regarding handedness and language evolution}

In an earlier section we argued that if populationlevel right-handedness for manual tool-using tasks was a characteristic of other great apes, and if stone tool-using hominins of a similar grade of brain size to those apes could also be shown to have been predominantly right-handed, then this would imply that a population-level preference for the right hand as the manipulator could have evolved under selection for non-communicative manual praxis. In fact, we have not found unequivocal evidence in support of that argument. Studies with the Tube task have indicated a right-handed bias in three captive chimpanzee populations, although the effect is comparatively weak; but this pattern has not yet been replicated in naturalistic tasks in wild chimpanzee populations, nor in captive populations of the two other species of African ape (gorilla and bonobo). Population-level right-handedness has also not yet been demonstrated in an experimentally well-validated approach to lithic evidence from Oldowan industries. In opposition to this we summarized recent versions of the Homo loquens argument, in which it is lateralization of speech and language processes that drives the evolution of human handedness. At present, we have evidence of population-level right handedness in tool use in Homo heidelbergensis, Neanderthals and anatomically modern Homo sapiens; these hominins are all relatively large-brained. We also have (although not reviewed here) suggestive evidence of speech-relevant adaptations in the same three species from hyoid bone morphology (Arensburg et al. 1989; Martínez et al. 2008) and from ancient DNA (the presence of the human form of FOXP2 in Neanderthals: Krause et al. 2007). 
If it is correctly interpreted as such, then this coincidence of evidence for speech adaptations with that just reviewed for population-level right handedness would seem to support the language-first hypothesis. But the jury is still out.

\section{Acknowledgements}

The authors would like to thank John Robb and two anonymous reviewers for helpful comments on previous drafts of this paper. N.U. is grateful to Lambros Malafouris and Colin Renfrew for the opportunity to participate in the stimulating conference that led to this paper, the Lejre Historical-Archaeological Research Center, Southampton University Department of Archaeology, Farina Sternke and Marco Peresani. J.S. acknowledges assistance from the EC FP6 HANDTOMOUTH project, contract no. 29065.

\section{Notes}

1. In a recent argument for the tool-use-first scenario, Krifka (2007) drew attention to analogous manual role specialization in both co-speech gesturing (where analogical, iconic or indexical gestures support and illustrate the spoken message), and human sign languages. In co-speech gesturing, Enfield (2004) analysed instances where one hand is passive (held still) while the other articulates some representational gesture. In such cases, the non-dominant hand carries forward its form from a previous utterance, showing continuity in the topic and establishing a frame of reference, while the dominant hand represents some new information that constitutes a comment on that topic. In conventionalized sign languages, the non-dominant hand plays a minor role in lexical representation, often framing or providing context in an utterance, by acting for example as a place of articulation by the dominant hand; as a classifier signalling the more general semantic class (such as the subject, while the dominant hand describes some predicate); as a marker of prosodic boundaries; or to express discourse coherence (Krifka 2007). This latter role is similar to that described by Enfield for cospeech gesturing, with the non-dominant hand carrying forward a representation of the discourse topic while the dominant hand adds information in the form of continuing comment. Liddell (2003) refers to such signs made by the non-dominant hand as 'buoys', signs which serve as conceptual landmarks while the dominant hand continues to add comments or describe predicates. Krifka (2007) sees this pattern of manual specialization as closely analogous to that seen in tool-using tasks, where the non-dominant hand supports the topic for the dominant hand to act ('comment') on it; he suggests that manual specialization in object manipulation may therefore have served as a preadaptation for the pragmatic topic-comment organization which is a universal feature of linguistic communication.
James Steele
AHRC Centre for the Evolution of Cultural Diversity
Institute of Archaeology
University College London
$31-34$ Gordon Square
London
WC1H OPY
UK

Email: j.steele@ucl.ac.uk

Natalie Uomini School of Archaeology, Classics and Egyptology

Hartley Building

University of Liverpool

Brownlow Hill

Liverpool

L69 3GS

UK

Email: N.Uomini@liv.ac.uk

\section{References}

Ahern, J.C.M., I. Karavanić, M. Paunović, I. Janković \& F.H. Smith, 2004. New discoveries and interpretations of hominid fossils and artifacts from Vindija Cave, Croatia. Journal of Human Evolution 46, 27-67.

Amunts, K., G. Schlaug, A. Schleicher et al., 1996. Asymmetry in the human motor cortex and handedness. NeuroImage 4, 216-22.

Amunts, K., F. Schmidt-Passos, A. Schleicher \& K. Zilles, 1997. Postnatal development of interhemispheric asymmetry in the cytoarchitecture of human area 4 . Anatomy and Embryology 196, 393-402.

Amunts, K., A. Schleicher, U. Burgel, H. Mohlberg, H.B. Uylings \& K. Zilles, 1999. Broca's region revisited: cytoarchitecture and intersubject variability. Journal of Comparative Neurology 412(2), 319-41.

Amunts, K., A. Schleicher, A. Ditterich \& K. Zilles, 2003. Broca's region: cytoarchitectonic asymmetry and developmental changes. Journal of Comparative Neuro$\log y 465,72-89$.

Annett, M., 1972. The distribution of manual asymmetry. British Journal of Psychology 3, 343-58.

Arbib, M.A., 2006. Aphasia, apraxia and the evolution of the language-ready brain. Aphasiology 20, 1125-55.

Arensburg, B., A.M. Tillier, B. Vandermeersch, H. Duday, L.A. Schepartz \& Y. Rak, 1989. A Middle Palaeolithic human hyoid bone. Nature 338, 758-60.

Ashton, N., 1988. Tranchet axe manufacture from Cliffe, Kent. Proceedings of the Prehistoric Society 54, 315-20.

Athènes, S., I. Sallagoïty, P.-G. Zanone \& J.-M. Albaret, 2004. Evaluating the coordination dynamics of handwriting. Human Movement Science 23(5), 621-41.

Aziz-Zadeh, L., L. Koski, E. Zaidel, J. Mazziotta \& M. Iacoboni, 2006. Lateralization of the human mirror neuron system. Journal of Neuroscience 26, 2964-70. 
Bailey, F.L., 1942. Navaho motor habits. American Anthropologist, n.s. 44, 210-34.

Bates, E. \& F. Dick, 2002. Language, gesture and the developing brain. Developmental Psychobiology 40, 293-310.

Bennett, A.J., S.J. Suomi \& W.D. Hopkins, 2008. Effects of early adverse experiences on behavioural lateralisation in rhesus monkeys (Macaca mulatta). Laterality 13, 282-92.

Bermúdez de Castro, J.M., T.G. Bromage \& Y.F. Jalvo, 1988. Buccal striations on fossil human anterior teeth: evidence of handedness in the middle and early Upper Pleistocene. Journal of Human Evolution 17(4), 403-12.

Bishop, D.V.M., 1989. Does hand proficiency determine hand preference? British Journal of Psychology 80, 191-9.

Bradshaw, J.L., 1991. Animal asymmetry and human heredity: dextrality, tool use and language in evolution - 10 years after Walker (1980). British Journal of Psychology $82,39-59$.

Bradshaw, J.L. \& N.C. Nettleton, 1982. Language lateralization to the dominant hemisphere: tool use, gesture and language in hominid evolution. Current Psychology 2, 171-92.

Bril, B., V. Roux \& G. Dietrich, 2005. Stone knapping: Khambhat (India), a unique opportunity? in Stone Knapping: the Necessary Conditions for a Uniquely Hominin Behaviour, eds. V. Roux \& B. Bril. (McDonald Institute Monographs.) Cambridge: McDonald Institute for Archaeological Research, 53-71.

Bryden, M.P., 1977. Measuring handedness with questionnaires. Neuropsychologia 15(4-5), 617-24.

Buxhoeveden, D.P., A.E. Switala, M. Litaker, E. Roy \& M.F. Casanova, 2001. Lateralization of minicolumns in human planum temporale is absent in non-human primate cortex. Brain, Behavior and Evolution 57, 349-58.

Byrne, R.W. \& J.M. Byrne, 1991. Hand preferences in the skilled gathering tasks of mountain gorillas (Gorilla g. berengei). Cortex 27(4), 521-46.

Byrne, R.W., N. Corp \& J.M. Byrne, 2001. Manual dexterity in the gorilla: bimanual and digit role differentiation in a natural task. Animal Cognition 4, 347-61.

Cantalupo, C. \& W.D. Hopkins, 2001. Asymmetric Broca's area in great apes. Nature 414, 505.

Chance, S.A. \& T.J. Crow, 2007. Distinctively human: cerebral lateralisation and language in Homo sapiens. Journal of Anthropological Sciences 85, 83-100.

Chapelain, A. \& E. Hogervorst, 2009. Hand preferences for bimanual coordination in 29 bonobos (Pan paniscus). Behavioural Brain Research 196(1), 15-29.

Clot, A., M. Menu \& P. Walter, 1995. Manières de peindre des mains à Gargas et Tibiran (Hautes-Pyrénées). L'Anthropologie 99(2/3), 221-35.

Corballis, M.C., 2003a. Out on a limb. Laterality 8, 195-200.

Corballis, M.C., 2003b. From mouth to hand: gesture, speech, and the evolution of right-handedness. Behavioral and Brain Sciences 26, 199-260.

Cornford, J.M., 1986. Specialized resharpening techniques and evidence of handedness, in La Cotte de St. Brelade 1961-1978: Excavations by C.B.M. McBurney, eds. P.
Callow \& J.M. Cornford. Norwich: Geo Books, 337-51, 413-14.

Crow, T.J., 1998. Sexual selection, timing and the descent of man: a theory of the genetic origins of language. Cahiers de Psychologie Cognitive 17, 1079-114.

Delluc, B. \& G. Delluc, 1993. Images de la main dans notre préhistoire. Les Dossiers d'Archéologie 178, 32-45.

Desrosiers, P., 1997. La posture des tailleurs de pierre. Maîtrise de préhistoire, Département d'Ethnologie, de Sociologie Comparative, d'Ethnomusicologie et de Préhistoire, Université Paris X - Nanterre.

Enfield, N.J., 2004. On linear segmentation and combinatorics in co-speech gesture: a symmetry-dominance construction in Lao fish trap descriptions. Semiotica 149, 57-123.

Eshed, V., A. Gopher, E. Galili \& I. Hershkovitz, 2004. Musculoskeletal stress markers in Natufian huntergatherers and Neolithic farmers in the Levant: the upper limb. American Journal of Physical Anthropology 123(4), 303-15.

Fagard, J. \& D. Corroyer, 2003. Using a continuous index of laterality to determine how laterality is related to interhemispheric transfer and bimanual coordination in children. Developmental Psychobiology 43, 44-56.

Faurie, C. \& M. Raymond, 2005. Handedness frequency over more than 10,000 years. Proceedings of the Royal Society of London B, 271 (1536), S43-S45.

Fernández-Jalvo, Y. \& J.M. Bermúdez de Castro, 1988. Buccal striations on the hominid anterior teeth from Atapuerca (Spain), in Scanning Electron Microscopy in Archaeology, ed. S.L. Olsen. (British Archaeological Reports International Series.) Oxford: Archaeopress, 386-401.

Fischer, A., 1990. On being a pupil of a flintknapper of 11,000 years ago, in The Big Puzzle. International Symposium on Refitting Stone Artefacts, eds. E. Cziesla, S. Eickhoff, N. Arts \& D. Winter. Bonn: Holos Verlag, 447-64.

Fisher, S.E., 2005. Dissection of molecular mechanisms underlying speech and language disorders. Applied Psycholinguistics, 26, 111-28.

Fogassi, L. \& P.F. Ferrari, 2007. Mirror neurons and the evolution of embodied language. Current Directions in Psychological Science 16, 136-41.

Fox, C.L. \& D.W. Frayer, 1997. Non-dietary marks in the anterior dentition of the Krapina Neanderthals. International Journal of Osteoarchaeology 7(2), 133-49.

Gannon, P.J., R.L. Holloway, D.C. Broadfield \& A.R. Braun, 1998. Asymmetry of chimpanzee planum temporale: humanlike pattern of Wernicke's brain language area homolog. Science 279, 220-22.

Gannon, P.J., N. Kheck \& P.R. Hof, 2008. Leftward interhemispheric asymmetry of macaque monkey temporal lobe language area homolog is evident at the cytoarchitectural, but not gross anatomic level. Brain Research 1199, 62-73.

Gentilucci, M. \& M.C. Corballis, 2006. From manual gesture to speech: a gradual transition. Neuroscience and Biobehavioral Reviews 30, 949-60.

Gibson, K.R. \& S. Jessee, 1999. Language evolution and expansions of multiple neurological processing areas, 
in The Origins of Language: What Non-human Primates can tell us, ed. B.J. King. Santa Fe (NM): School of American Research Press.

Goble, D.J. \& S.H. Brown, 2008. The biological and behavioral basis of upper limb asymmetries in sensorimotor performance. Neuroscience and Biobehavioral Reviews 32, 598-610.

Grafton, S.T., E. Hazeltine \& R.B. Ivry, 2002. Motor sequence learning with the nondominant left hand: a PET functional imaging study. Experimental Brain Research 146, 369-78.

Guiard, Y., 1987a. Asymmetric division of labor in human skilled bimanual action: the kinematic chain as a model. Journal of Motor Behavior 19(4), 486-517.

Guiard, Y., 1987b. Precursors to what? Theory is wanted for handedness in humans. Open peer commentary on 'Primate handedness reconsidered', by P.F. MacNeilage, M.G. Studdert-Kennedy \& B. Lindblom. Behavioral and Brain Sciences 10, 276-7.

Haaland, K.Y., J.L. Prestopnik, R.T. Knight \& R.R. Lee, 2004. Hemispheric asymmetries for kinematic and positional aspects of reaching. Brain 127(5), 1145-58.

Healey, J.M., J. Liederman \& N. Geschwind, 1986. Handedness is not a unidimensional trait. Cortex 22(1), 33-53.

Hinckley, K., 1996. Haptic Issues for Virtual Manipulation. PhD thesis, Computer Science Department, School of Engineering and Applied Science, University of Virginia. http://research.microsoft.com/Users/kenh/thesis/.

Hinckley, K., R. Pausch, D. Proffitt, J. Patten \& N. Kassell, 1997. Cooperative bimanual action, in ACM CHI'97 Conference on Human Factors in Computing Systems, eds. S. Pemberton, C. Ware and D. Wixon, 27-34. http://sigchi.org/chi97/proceedings/paper/kh.htm.

Hopkins, W.D., 2006. Comparative and familial analysis of handedness in Great Apes. Psychological Bulletin 132, 538-59.

Hopkins, W.D. \& S. Fernandez-Carriba, 2002. Laterality in communicative behaviors in non-human primates: a critical analysis, in Comparative Vertebrate Lateralization, eds. L. Rogers \& R. Andrew. Oxford: Oxford University Press, 445-79.

Hopkins, W.D. \& L. Marino, 2000. Asymmetries in cerebral width in non-human primate brains as revealed by magnetic resonance imaging (MRI). Neuropsychologia 38, 493-9.

Hopkins, W.D. \& D.M. Rabinowitz, 1997. Manual specialisation and tool use in captive chimpanzees (Pan troglodytes): the effect of unimanual and bimanual strategies on hand preference. Laterality 2, 267-77.

Hopkins, W.D., L. Marino, J.K. Rilling \& L.A. MacGregor, 1998. Planum temporale asymmetries in great apes as revealed by magnetic resonance imaging (MRI). NeuroReport 9, 2913-18.

Hopkins, W.D., S. Fernanadez-Carriba, M.J. Wesley, A. Hostetter, D. Pilcher \& S. Poss, 2001. The use of bouts and frequencies in the evaluation of hand preferences for a coordinated bimanual task in chimpanzees (Pan troglodytes): an empirical study comparing two different indices of laterality. Journal of Comparative Psychology 115, 294-9.

Hopkins, W.D., T.S. Stoinski, K.E. Lukas, S.R. Ross \& M.J. Wesley, 2003. Comparative assessment of handedness for a coordinated bimanual task in chimpanzees ( $P a n$ troglodytes), gorillas (Gorilla gorilla) and orangutans (Pongo pygmaeus). Journal of Comparative Psychology 117, 302-8.

Hopkins, W.D., M.J. Wesley, M.K. Izard, M. Hook \& S.J. Schapiro, 2004. Chimpanzees (Pan troglodytes) are predominantly right-handed: replication in three populations of apes. Behavioral Neuroscience 118, 659-63.

Hopkins, W.D., J.P. Taglialatela, A. Meguerditchian, T. Nir, N.M. Schenker \& C.C. Sherwood, 2008. Gray matter asymmetries in chimpanzees as revealed by voxelbased morphometry. NeuroImage 42, 491-7.

Johansen, L., 1996. Flinthuggerens værksted ? - forsøg med flinthugning, in Arkæologiske Eksperimenter i Lejre, eds. M. Meldgaard \& M. Rasmussen. Lejre: Rhodos, 9-15.

Kirby, S., 2000. Syntax without natural selection: how compositionality emerges from vocabulary in a population of learners, in The Evolutionary Emergence of Language: Social Function and the Origins of Linguistic Form, ed. C. Knight. Cambridge: Cambridge University Press, 303-23.

Kirby, S., M. Dowman, \& T. Griffiths, 2007. Innateness and culture in the evolution of language. Proceedings of the National Academy of Sciences of the USA 104(12), 5241-5.

Kirchner, L., 1959. Jungpaläolitische Handdarstellungen der Franko-kantabrischen Felsbilderzone. Ein Versuch ihrer Deutung unter Berücksichtigung ethnographischer Parallelen. PhD thesis, Bern University. Göppingen: Werner-Müller-Verlag.

Krause, J., C. Lalueza-Fox, L. Orlando, et al., 2007. The derived FOXP2 variant of modern humans was shared with Neandertals. Current Biology 17, 1908-12.

Krifka, M., 2007. 'Functional similarities between bimanual coordination and topic/comment structure', in Working Papers of the SFB632, eds. S. Ishihara, S. Jannedy \& A. Schwarz. Interdisciplinary Studies on Information Structure 8, 61-96.

Leonardi, P., 1979. Una serie di ritoccatoi prevalentemente mustieriani del Riparo Tagliente in Valpantena presso Verona. Preistoria Alpina 15, 7-15.

Liddell, S.K., 2003. Grammar, Gesture, and Meaning in American Sign Language. Cambridge: Cambridge University Press.

Liepmann, H., 1905. Die linke Hemisphäre und das Handeln. Münchener Medizinische Wochenschrift 49, 2322-6.

Lonsdorf, E.V. \& W.D. Hopkins, 2005. Wild chimpanzees show population-level handedness for tool use. Proceedings of the National Academy of Sciences of the USA 102, 12,634-8.

Lozano, M., J.M., Bermúdez de Castro, E. Carbonell \& J.L. Arsuaga, 2008. Non-masticatory uses of anterior teeth of Sima de los Huesos individuals (Sierra de Atapuerca, Spain). Journal of Human Evolution 55, 713-28. 
Ludwig, B.V. \& J.W.K. Harris, 1994. Handedness and knapping skill: their effects on Plio-Pleistocene lithic assemblage variability, in Pre-circulated papers of the 3rd World Archaeological Congress, New Delhi, 4-11 Dec. 1994. New Delhi: World Archaeological Congress.

MacNeilage, P.F., 1998. The frame/content theory of evolution of speech production. Behavioral and Brain Sciences 21, 499-546.

MacNeilage, P.F., M.G. Studdert-Kennedy \& B. Lindblom, 1984. Functional precursors to language and its lateralization. American Journal of Physiology: Regulatory, Integrative and Comparative Physiology 15, 912-14.

MacNeilage, P.F., M.G. Studdert-Kennedy \& B. Lindblom, 1987. Primate handedness reconsidered. Behavioral and Brain Sciences 10, 247-303.

Magill, R.A., 1993. Motor Learning. Concepts and Applications. Madison (WI): Brown and Benchmark.

Marchant, L.F. \& W.C. McGrew, 2007. Ant fishing by wild chimpanzees is not lateralised. Primates 48, 22-6.

Marchant, L.F., W.C. McGrew \& I. Eibl-Eibesfeldt, 1995. Is human handedness universal? Ethological analyses from three traditional cultures. Ethology 101(3), 239-58.

Martin, H., 1923. L'homme Fossile de la Quina. Paris: Doin.

Martínez, I., J.-L. Arsuaga, R. Quam, J.-M. Carretero, A. Gracia \& L. Rodríguez, 2008. Human hyoid bones from the middle Pleistocene site of the Sima de los Huesos (Sierra de Atapuerca, Spain). Journal of Human Evolution 54, 118-24.

McGrew, W.C., 1974. Tool use by wild chimpanzees in feeding upon driver ants. Journal of Human Evolution 3, 501-8.

McGrew, W.C. \& L.F. Marchant, 1997. On the other hand: current issues in and meta-analysis of the behavioural laterality of hand function in non-human primates. Yearbook of Physical Anthropology 40, 201-32.

Molnar-Szakacs, I., J. Kaplan, P.M. Greenfield \& M. Iacoboni, 2006. Observing complex action sequences: the role of the fronto-parietal mirror neuron system. NeuroImage 33, 923-35.

Newcomer, M.H. \& G.d.G. Sieveking, 1980. Experimental flake scatter-patterns: a new interpretative technique. Journal of Field Archaeology 7(3), 345-52.

Oldfield, R.C., 1971. The assessment and analysis of handedness: the Edinburgh inventory. Neuropsychologia 9(1), 97-113.

Patterson, L.W. \& J.B. Sollberger, 1986. Comments on Toth's right-handedness study. Lithic Technology 15, 109-11.

Pelegrin, J., 2005. Remarks about archaeological techniques and methods of knapping: elements of a cognitive approach to stone knapping, in Stone Knapping: the Necessary Conditions for a Uniquely Hominin Behaviour, eds. V. Roux \& B. Bril. (McDonald Institute Monographs.) Cambridge: McDonald Institute for Archaeological Research, 23-33.

Petkov, C.I., C. Kayser, T. Steudel, K. Whittingstall, M. Augath \& N.K. Logothetis, 2008. A voice region in the monkey brain. Nature Neuroscience 11, 367-74.

Pickering, T.R. \& B. Hensley-Marschand, 2008. Cutmarks and hominid handedness. Journal of Archaeological Science 35, 310-15.

Pilcher, D.L., E.A. Hammock \& W.D. Hopkins, 2001. Cerebral volumetric asymmetries in non-human primates: a magnetic resonance imaging study. Laterality 6, 165-79.

Pobiner, B.L., 1999. The use of stone tools to determine handedness in hominids. Current Anthropology 40(1), 90-92.

Poremba, A., M. Malloy, R.C. Saunders, R.E. Carson, P. Herscovitch \& M. Mishkin, 2004. Species-specific calls evoke asymmetric activity in the monkey's temporal poles. Nature 427, 448-51.

Provins, K.A., 1997a. Handedness and speech: a critical reappraisal of the role of genetic and environmental factors in the cerebral lateralization of function. Psychological Review 104(3), 554-71.

Provins, K.A., 1997b. The specificity of motor skill and manual asymmetry: a review of the evidence and its implications. Journal of Motor Behavior 29(2), 183-92.

Rilling, J.K., 2006. Human and non-human primate brains: are they allometrically scaled versions of the same design? Evolutionary Anthropology 15, 65-77.

Rilling, J.K. \& T.R. Insel, 1999. The primate neocortex in comparative perspective using magnetic resonance imaging. Journal of Human Evolution 37, 191-223.

Ringo, J.L., 1991. Neuronal interconnection as a function of brain size. Brain, Behaviour, and Evolution 38, 1-6.

Ringo, J.L., R.W. Doty, S. Demeter \& P.Y. Simard, 1994. Time is of the essence: a conjecture that hemispheric specialization arises from interhemispheric conduction delay. Cerebral Cortex 4, 331-43.

Ringot, J.L., 2003. Der Steinzeitmensch als Sprayer? Neue Hypothese zum Farbauftrag der Steinzeitmalerei, in Experimentelle Archäologie in Europa, ed. M. Fansa. (Bilanz 2002 - Heft 1.) Oldenburg: Isensee Verlag, 65-9.

Rizzolatti, G. \& M.A. Arbib, 1998. Language within our grasp. Trends in Neuroscience 21, 188-94.

Roberts, M.B. \& S.A. Parfitt, 1999. Boxgrove: a Middle Pleistocene Hominid Site at Eartham Quarry, Boxgrove, West Sussex, vol. 1. (Archaeological Report 17.) London: English Heritage.

Roy, A. \& M. Arbib, 2005. 'The syntactic motor system', in Gestural communication in non-human and human primates, eds. K. Liebal, C. Muller \& S. Pika. Gesture $5,7-37$.

Sakata, H. \& M. Taira, 1994. Parietal control of hand action. Current Opinion in Neurobiology 4, 847-56.

Schmitt, V., S. Melchisedech, K. Hammerschmidt \& J. Fischer, 2008. Hand preferences in Barbary macaques (Macaca sylvanus). Laterality 13, 143-57.

Semenov, S.A., 1964. Prehistoric Technology. London: Cory, Adams and Mackay.

Sherwood, C.C., E. Wahl, J.M. Erwin, P.R. Hof \& W.D. Hopkins, 2007. Histological asymmetries of primary motor cortex predict handedness in chimpanzees (Pan troglodytes). Journal of Comparative Neurology 503, 525-37. 
Sherwood, C., F. Subiaul \& T. Zawidzki, 2008. A natural history of the human mind: tracing evolutionary changes in brain and cognition. Journal of Anatomy 212, 426-54.

Spinozzi, G., M.G. Castorina \& V. Truppa, 1998. Hand preferences in unimanual and coordinated-bimanual tasks by tufted capuchin monkeys (Cebus apella). Journal of Comparative Psychology 112, 183-91.

Steele, J., 2000a. Skeletal indicators of handedness, in Human Osteology, eds. M. Cox \& S. Mays. London: Greenwich Medical Media, 307-23.

Steele, J., 2000b. Handedness in past human populations: skeletal markers. Laterality 5, 193-220.

Steele, J. \& N.T. Uomini, 2005. Humans, tools and handedness, in Stone Knapping: the Necessary Conditions for a Uniquely Hominin Behaviour, eds. V. Roux \& B. Bril. (McDonald Institute Monographs.) Cambridge: McDonald Institute for Archaeological Research, 217-39.

Steenhuis, R.E. \& M.P. Bryden, 1989. Different dimensions of hand preference that relate to skilled and unskilled activities. Cortex 25, 289-304.

Steklis, H.D. \& S. Harnad, 1976. 'From hand to mouth: some critical stages in the evolution of language', in Origins and evolution of language and speech, eds. S. Harnad, H.D. Steklis \& J.B. Lancaster. Annals of the New York Academy of Sciences 280, 445-55.

Stout, D., 2002. Skill and cognition in stone tool production: an ethnographic case study from Irian Jaya. Current Anthropology 43(5), 693-722.

Stout, D., 2003. Stone Tools and the Evolution of Human Thinking: Cultural, Biological and Archaeological Elements in an Anthropology of Human Origins. Unpublished PhD thesis, Archaeology Department, Indiana University, Bloomington.

Stout, D., N. Toth, K. Schick \& T. Chaminade, 2008. Neural correlates of Early Stone Age tool-making: technology, language and cognition in human evolution. Philosophical Transactions of the Royal Society B 363, 1939-49.

Taglialatela, J.P., C. Cantalupo \& W.D. Hopkins, 2006. Gesture handedness predicts asymmetry in the chimpanzee inferior frontal gyrus. Neuroreport 17, 923-7.

Taglialatela, J.P., J.L. Russell, J.A. Schaeffer \& W.D. Hopkins, 2008. Communicative signalling activates 'Broca's' homolog in chimpanzees. Current Biology 18, 343-8.

Todor, J.L. \& T. Doane, 1977. Handedness classification: Preference versus proficiency. Perceptual and Motor Skills 45, 1041-2.

Toth, N., 1985. Archaeological evidence for preferential right-handedness in the Lower and Middle Pleistocene, and its possible implications. Journal of Human Evolution 14(6), 607-14.

Trinkaus, E., 1983. The Shanidar Neandertals. New York (NY): Academic Press.
Uomini, N.T., 2005. A Study of Interindividual Variation in Bimanual Knapping Configurations, and the Effects of Handedness on Knapping Products. Technical report of experiments undertaken July 2005. Lejre: Lejre Historical-Archaeological Research Centre,

Uomini, N.T., 2008a. In the Knapper's Hands: Testing Markers of Laterality in Hominin Lithic Production, with Reference to the Common Substrate of Language and Handedness. Unpublished PhD thesis, Archaeology Department, University of Southampton, UK.

Uomini, N.T., 2008b. In the knapper's hands: identifying handedness from lithic production \& use, in 'Prehistoric Technology' 40 Years Later: Functional Studies and the Russian Legacy, eds. L. Longo \& N. Skakun. (British Archaeological Reports International Series 1783.) Oxford: Archaeopress, 51-62.

Uomini, N.T., in press. Handedness in Neanderthals, in Neanderthal Lifeways, Subsistence and Technology, eds. N.J. Conard \& J. Richter. Heidelberg: Springer.

Vauclair, J., A. Meguerditchian \& W.D. Hopkins, 2005. Hand preferences for unimanual and coordinated bimanual tasks in baboons (Papio anubis). Cognitive Brain Research 25, 210-16.

Verstynen, T., J. Diedrichsen, N. Albert, P. Aparicio \& R.B. Ivry, 2005. Ipsilateral motor cortex activity during unimanual hand movements relates to task complexity. Journal of Neurophysiology 93, 1209-22.

Wenban-Smith, F.F., 1997. Raiders of the lost part. Lithics 17/18, 87-90.

Weyer, E., 1959. Primitive Peoples Today: a Uniquely Revealing Account of Life Outside Civilization. London: Hamish Hamilton.

White, M.J., 1998. Twisted ovate bifaces in the British Lower Palaeolithic, in Stone Age Archaeology. Essays in Honour of John Wymer, eds. N. Ashton, F. Healy \& P. Pettit. (Oxbow Monograph 102.) Oxford: Oxbow Books, 98-104.

Willems, R. \& P. Hagoort, 2007. Neural evidence and the interplay between language, gesture and action: a review. Brain and Language 101, 278-89.

\section{Author biographies}

James Steele is a Reader in Archaeology at University College London. He specializes in the archaeology of prehistoric human dispersals, and in the evolution of human speech and language. James is Director of the AHRC Centre for the Evolution of Cultural Diversity.

Natalie Uomini is a Postdoctoral Researcher in the British Academy's Centenary Research project 'Lucy to Language - the Archaeology of the Social Brain'.

She is interested in the origins of language and how it relates to hand preference and brain lateralization. Natalie is currently studying Palaeolithic artefacts in relation to motor control, complexity and lateralized hand-use. 